\title{
Registro de Jorge Carrera Andrade ${ }^{1}$
}

\author{
Mundo, viaje y poesía
}

$E^{L}$ título que Carrera Andrade puso a la colección de sus poesías, Registro del mundo, nos reveló la medida $\mathrm{y}$, aun más, la calidad de su ambición de artista. Registrar el mundo, andarlo, buscarle las vueltas, entrándose en todos sus escondrijos. Dejar consignado en anchas hojas blancas el inventario de esta faena inquisidora, confeccionando algo así como un catálogo de las bellezas terrenales. ¿Pero cómo llevar a cumplimiento proyecto tan ardido?

La poesía, en general, y muy especialmente la moderna, podría ponerse bajo la advocación de un santo patrono pagano, aquel gran griego viajero, Ulises el movedizo. Túvole por feliz entre los felices cierto excelente poeta francés porque había hecho un beau voyage. Poetas modernos hay que tacharían de pleonástica esta expresión. Con decir viaje basta y sobra, porque el viaje es bello, de por sí. Frente al estilo de vivir horaciano, la poesía suya del estarse quieto, "del monte en la ladera", la época moderna alza mesnada por el estilo de vida andariego y errabundo, por la poesía de lo viajero. Carrera Andrade la siente en lo más hondo de sí, percibe su

$$
\begin{aligned}
& \text {... sangre llena de navíos } \\
& \text { que vienen y se van a cada instante. }
\end{aligned}
$$

Pululan por las páginas de sus poesías aleteantes nombres de esos que se encuentran posados en los mapas: nombres de ríos y de mares y de ciudades, de dos o tres continentes. Carrera Andrade "ha visto mucho mundo", según el lugareño dicho castellano. $Y$ nos lo ofrece en su poesía, generosamente: 
He aquí un vasto mundo con su envoltura de maravilla.

Maravillosa, sí, la "envoltura del mundo". Su haz, lo que se ve. Y para este poeta, en las primeras etapas de su aventura cósmica eso es todo el mundo, y a eso, a esa envoltura maravillosa se reduce todo él. Entonces, queriéndolo o sin querer, escribió su arte poética, en el poema que tituló "El objeto y su sombra". He aquí el verso más gallardamente doctrinal de este poema:

$$
\text { Las cosas, o sea la vida. }
$$

Esto es, esa vaga entidad que llamamos vida se reduce a las cosas que nos circundan, está fuera de nosotros. "Todo el universo es presencia." La vida no es el pensamiento, ni el sueño. La abstracción muere en un segundo. En las manos nos queda la suculenta realidad que es, dice Carrera Andrade, "más cabal que el sueño". Así ingresa nuestro poeta en la favorecida secta, que tuvo por gran sacerdote a Teóphile Gautier, de los creyentes en el mundo exterior, adoradores de las formas. En consecuencia, a renglón seguido ordena:

$$
\begin{aligned}
& \text { Limpiad el mundo -esta es la clave- } \\
& \text { de fantasmas del pensamiento. }
\end{aligned}
$$

\section{El pensamiento, desterrado}

Ya sabemos, pues, lo que entiende por "la sombra del objeto": la abstracción, el sueño, esos fantasmas del pensar. Los aparta de su lado para quedarse solo con las cosas mondas y lirondas, en su perfecta concreción formal. Eso es "el objeto". La función del poeta habrá de ser la caza de cosas, de objetos, pertenecientes a esa enorme fauna de la presencia que puebla la corteza del mundo y del tiempo. Para alcanzarlo, el arma buena no será la saeta, ni el rifle: los ojos. Cazador con los ojos, es Carrera Andrade. Ojos viajeros, que den ardorosas batidas por todos los rincones de nuestra selva terrenal, en busca de las cosas. Termina su "arte poética" con un sumo acierto: 
Que el ojo apareje su nave

Para un nuevo descubrimiento.

La poesía, largo incesante viajar de la vista. En España, alguien dijo, y el pueblo nunca lo olvidó, en esa firme memoria del refrán: "Vivir para ver".

\section{Vista y visión}

Mallarmé soñó con una isla. Es en la Prose pour des Esseintes. Perfecta, porque aúna la seguridad y la figuración. Era

$$
\begin{aligned}
& \text {. une the que l'air charge } \\
& \text { de vue et non de visions. }
\end{aligned}
$$

Nos invita así, aunque escurriéndose como solía, tras el burladero del equívoco, a distinguir entre lo captable, o captado, materialmente por los ojos, vue, y lo asequible, sólo, por arte de la imaginación, visions. Entre el objeto visto, y el que yo llamaría visionado. A este segundo es al que vuelve la espalda desdeñosamente Carrera Andrade, para echarse a los pies, enamorado ferviente, del objeto visto. Pero ¿ es tan hacedero como parece eso de ver? Ruskin, veedor de oficio, nos decía en sus Modern Painters: "La cosa más grande que un alma humana puede hacer en este mundo es ver. Por una persona que piense hay miles que no hacen más que hablar. Pero de mil que piensen, no hay más que uno que vea". Ese uno entre miles, quiere serlo nuestro poeta. Zarpa en su nave, sin más tripulante que su heroico empeño visual. Pero sospecho que fracasa por completo. Que no sabe ver. Por eso es tan auténtico poeta.

Intentaré explicar esa sospecha, comprobando si el poeta logra su anhelo de desprender las cosas que quiere ver, de su sombra, de toda abstracción, sueño o fantasma del pensamiento.

Una cierta tarde se ve frente a dos cosas, simples, elementales: la tarde $y$ una golondrina que la surca con su vuelo. $Y$ escribe:

Si la tarde es un navío la golondrina es su ancla. 
Otra vez oye a un pájaro, piando:

E1 pájaro es el periódico de la mañana en el campo.

Más adelante dice, al pensar en un libro:

Un libro es una casa con ventanas al campo.

$Y$ frente a un espejo, lo define así:

El espejo es la puerta estrecha hacia un enigma de cristal.

Podrían citarse ejemplos y ejemplos similares. Cualquier poesía de Carrera Andrade funciona como una de esas cajitas de sorpresa, que con sólo levantar su tapa, o verso inicial, disparará hacia nosotros enérgicamente, la figura colorinesca y graciosa de una imagen. Todas las cosas, las famosas cosas, los objetos puros, tras los cuales se afanaba, van invariablemente escoltadas por su traslación imaginativa y se nos ofrecen en brazos de una metáfora, sólo a través de una operación metafórica. La potencia y acierto metaforizantes de este poeta son realmente descomunales. Abunda mucho la poesía americana de habla española en grandes metaforistas, de diverso matiz. Un Lugones, un Herrera Reissig, un Gorostiza, por ejemplos entre los mejores. En punto a novedad y gallardía no les cede en nada $\mathrm{Ca}$ rrera Andrade. En el origen mismo de su sistema poético, reina, sin rival, el impulso determinante de la metáfora.

\section{La metáfora y las cosas}

Ya está arrumbada la vieja teoría de que la metáfora era una deliberada operación intelectual por la cual se traían a comparación dos cosas que ofrecían algún parecido. Hoy vemos la metáfora como acto poético puro, forma nueva de percepción poética, que brota de la aproximación de dos objetos que a veces no tienen semejanza alguna entre sí. Fué Vico quien llamó a la metáfora un mito en pequeño. $\mathrm{Y}$ sabemos que la metáfora para vivir necesita subyugar o matar. Cuando se encuentra a sí misma, creando una tercera reali- 
dad, lo hace alzándose sobre las ruinas de las dos cosas comparadas, que quedan esfumadas o muertas junto a la nueva y radiante cosa poética. Si Carrera Andrade nos dice que el pájaro es el periódico de la mañana en el campo los dos términos operantes de la metáfora son: de un lado un pájaro, de otro un diario matinal. Pero la resultante poética, no es precisamente un pájaro sino un pájaro acrecido, enriquecido, con toda la copia de nuevas luces que le viene de su confrontación con el periódico. Es: un pájaro + algo. $\mathrm{Y}$ análogamente el diario es: un diario + algo. Ese algo, esa tercera cosa, lo extra-pájaro, lo extra-periódico, constituyen la nueva realidad inventada por el poeta. Es el descubrimiento. ¿ Pero a qué costa se hace tal descubrir? El precio ha sido la desfiguración de dos cosas reales y distintas. La metáfora es una falta de respeto a la pura realidad objetiva de esos dos elementos de donde nace. El pájaro de esa metáfora citada, es ya un extraño avechucho, con cola de letras de imprenta, y pregonero de sucesos sensacionales. $\mathrm{Y}$ al periódico le han salido pico y habla, de pronto. Eso si nos obstinamos en seguir viendo separados los dos miembros primarios de la metáfora. ¿Cabe mayor inexactitud intelectual que llamar a un pájaro periódico, y viceversa? $Y$ sin embargo, la metáfora tan aludida es de milagrosa exactitud poética. ¿Y qué duda cabe de que el milagro ha sido operado no por "el ojo", que jamás podría confundir la hoja impresa con el ave, sino con la muy superior vista de la fantasía crẹadora? La metáfora empieza donde "el ojo" termina de ver y la imaginación comienza a visionar. No, las cosas no son más que el incentivo concreto de la actividad poetizante. En el primer paso del proceso poético hay dos objetos vistos; en el postrero un objeto visionado. Siem. pre se colgó al poeta la fama de ser un distraído, de no ver las cosas como los demás, en fin, de "ver visiones". Admirable dicho popular que designa exactamente la vista del poeta, esto es, su visión. Carrera Andrade no sabe ver, porque sabe visionar. Por muy militante que se nos declare del puro ver, la verdad es que toda cosa que se asoma a su poesía es absorbida en el acto por el ansia metaforizante, y transmutada en visión. Porque la metáfora es la forma plástica que toma la visión en poetas de corte sensual. Poeta de los ojos, sí, es Carrera Andrade. Pero los ojos ¿ven, sólo, miran sólo? “ ¿Crees que la visión, la visión misma, la flor más esplendente del conocer hizo al ojo? No, al ojo to hizo la vida, y el ojo hizo la visión, y luego por ministerio de la visión perfeccionó la vida al ojo... Sí, el 
ojo es para algo más hondo que para ver, es para alegrar el alma". Hasta aquí Miguel de Unamuno. Sólo con estas dilucidaciones podemos aceptar de plano, y con un nuevo significar, los dos últimos versos de "El objeto y su sombra":

Que el ojo apareje su nave para un nuevo descubrimiento.

\section{El tema de la ventana}

Presente está, en todas las épocas de la poesía de Carrera Andrade. Probemos a interpretarlo, aprovechando las observaciones que van hechas.

1927 Vidriera, libro de agua donde los ojos leen la unción matavillosa de los árboles.

1930 Ventana de cuatro vidrios.

Con tu cruz de madera eres un nicho abierto en el cielo para guardar nubes muertas.

1930 La ventana nació de un deseo de cielo $y$ en la muralla negra se posó como un ángel.

1937 Ventanas, puertas, claraboyas: intimas amigas cómplices de mi evasión de cada día.

$\mathrm{La}$ ventana es continua invitación al viaje.

1937 No poseo otro bien que la ventana que quiere ser a medias campo y cielo y en su frágil frontera con el mundo la presencia registra de las cosas. . .la ventana, mi propiedad mayor...

Es de notar que el tema de la ventana no sólo es repetido en la poesía de Carrera Andrade una y otra vez, sino que además está ligado por el poeta a las dos ideas básicas de su poesía: viaje y registro. Insistencias de este género no son jamás casuales ni insignificantes. Dijo Roger Fry, refiriéndose a Mallarmé, que lo que 
mejor caracteriza a un poeta es sus obsesiones. Así lo creo: suelen responder a una preocupación cardinal suya, y nos apuntan casi siempre al centro mismo de su concepto de la poética. (Recuérdese la "página blanca", en Mallarmé.) Eso me parece acontecer en el caso de Carrera Andrade. El hueco rectangular abierto en una pared, tiene para él magnético encanto. ¿Por qué? Su empeño poético es ver, nada más que ver, nos dijo: el ojo viajero (el ver) en su nave (el viajar) en busca de la antigüedad y que es de Doña Oliva Sabuco de Nantes, en su Coloquio del conocimiento de si mismo:

Púsole en lo más alto dos vidrieras a manera de ventanas del alma que son los ojos, para que por aquellas vidrieras, en abrién- dolas, viese su patria, que es el cielo y gozase de tanta variedad para él criada.

Carrera Andrade, poeta del ver, voluntario entusiasta de la función visual, tenía que ir fatalmente una y otra vez en busca de la ventana, de esos segundos ojos por los cuales se le entrega al hombre y se lo quita cada día, con el advenir del sol y el avance de la sombra, la maravillosa realidad de la corteza del mundo. No es la de Carrera Andrade la exasperada interpretación mística de Mallarmé en su poema "Les fenêtres". Es más bien, un encuentro entre el ansia de viajar baudelairiana, de la inquietud romántica y del goce sensual, de la famosa cupiditia oculorum de los teólogos.

Pero tiene ese misterioso rectángulo otra cualidad más, que nos explica su atractivo. Es la de encuadrar rigurosamente un fragmento de universo, de su tierra, su mar y su cielo, ceñirlo entre una ordenación de cuatro lineas y por ende hacerlo más asequible a nuestra momentánea posesión, casi diría hasta a nuestro dominio. Frente a un paisaje visto desde el exterior la mirada casi no tiene lindes, yerra confusa por la vastedad, y el hombre se siente abrumado, en su humana limitación, por la grandiosa ilimitación de lo que le rodea. En la oposición entre hombre y naturaleza, es ella la que triunfa a horizonte desplegado. Pero si el mismo objeto humano pone los ojos en idéntico paisaje, desde un cuarto, y tal y como lo cuadra el marco de una ventana, el panorama se encuentra, por el arte maravillosa, limitado también. Limitado por una sencilla obra del hombre, por ese cuadrángulo de madera. La observación entre el observador y lo observado ha sufrido un profundo trastorno. Por loca que sea la fi- 
guración puede el hombre que ha apresado al paisaje entre aquellas cuatro rectas, como en una esquemática jaula, figurarse que el paisaje es suyo, que lo ha metido en su casa, domesticado. $Y$ hasta se siente dueño de actuar no sobre la verdadera realidad de ese paisaje, pero sí sobre la realidad de cosas que descubrir y anotar (registro). $\mathrm{Y}$ ¿qué representan las ventanas, mejor dicho, qué han venido a representar en la habitación humana y en el lenguaje? La función primaria y humilde de la ventana es iluminar y ventilar, abrir el cerrado habitáculo a la luz y al aire. Misión que yo llamaría de fuera adentro, de la ventana. Pero un día alguien descubre uno de esos perogrullescos prodigios del hombre, y es que la ventana tiene otro menester, de dentro afuera, éste. Ver, desde un recinto cerrado, lo que hay, o lo que sucede en el vasto ámbito exterior. Enlazar al hombre clauso con el mundo abierto. La ventana cobra una significación altísima; actúa de puente entre lo interior y lo exterior y entre el hombre y el mundo. Sirve, sobre sus modestos oficios de iluminadora y ventiladora, para ver, para mirar al mundo. $Y$ ¿no es ese noble oficio exactamente similar al que cumplen en el cuerpo del hombre los ojos? Así se explica que desde hace muchos siglos ruede por varios idiomas esa metáfora en que se llama a los ojos las ventanas del alma. Quizá algunos anglosajones no sepan que la palabra window, que tan a menudo usan, contiene en su composición etimológica esa misma metáfora; ya que viene de wind, aire, viento, y auga, ojo. La imagen por la cual se compara la ventana a un ojo está por siempre anclada en una de las lenguas más habladas del orbe. Será pues la ventana un excelente medio de registro del mundo; por ella se ven, se miran las cosas, se escudriñan los horizontes. Para el hombre confinado la ventana es sus segundos ojos. Si en vez de partir de la palabra ventana, en esta averiguación psicológicolingüística, para ver cómo por ella accedemos a la noción de ojo seguimos ahora el camino contrario y arrancamos de la palabra ojo, veremos con sorpresa que recalamos, en la palabra ventana. Las citas corroborativas podrían ser docenas. Sólo traeré aquí dos. Aquélla en que Milton habla tan hermosamente de las miradas como de traficantes del alma con el cielo, en $I l$ penseroso:

And looks commercing with the skies

Thy rapt soul sitting in thine eyes. 
$Y$ otra, de las muchas que se corrieron por la literatura renacentista, desde su presencia, en este cuarto, haciéndolo aparecer o desaparecer a su antojo, con sólo abrir o cerrar la ventana. $Y$ de modular su extensión abriéndola más o menos. La ventana es un sutil engaño, falaz forma de posesión y señorío del mundo exterior por la voluntad del hombre. El dueño de una casa orientada a los cuatro puntos cardinales, y con 24 ventanas labradas en sus paredes, puede estar seguro de que 24 fragmentos del mundo exterior serán tan suyos como lo serían 24 falsos trozos de naturaleza trasladados en sendos lienzos y colgados en los muros de la casa. De suerte que la ventana hasta nos sirve para almacenar porciones de belleza natural, sin hurto ni deterioro posible. Carrera Andrade, cazador ocular de bellezas por el mundo, sabe muy bien todo lo que vale, para ojear las piezas de su gran caza mayor, primero, y para captarlas definitivamente después, la mágica potencia de la ventana.

\section{La sombra vengativa}

Así, durante años, por variadas tierras y climas, Carrera Andrade se ejercitó en el registro jubiloso de objetos sin sombra, de realidades sin fantasma. Pero en sus últimos libros esta roqueña convicción del poeta de que la vida se reduce a las cosas presentes, sin halo alguno de pensamiento, en su estricto contorno material, se ve peligrosamente combatida por oleajes atormentados de duda y de misterio. Al cabo de tantas andanzas por varios continentes y múltiples ciudades, entre muchedumbres de todos colores, después de tanto disfrutar de árboles, de frutas y de mapas, Carrera Andrade siente algo que no es precisamente visible por los ojos de lo visto, algo que es sólo sombra. En medio del día radiante de su poesía de la materia exaltada, se alza el fantasma de la soledad.

¿Dónde estuviste, soledad, que no te conoci hasta los veinte años?

$\mathrm{Y}$ aquel poeta que aconsejaba que se limpiara el mundo de fantasmas del pensamiento, dobla ahora el cuello, sumisamente, al imperio del fantasma:

Mas no hay nada que pueda librarnos de la soledad. 
Triste, resignada, admisión de la existencia de la sombra. $\mathrm{Ni}$ Peter Schlemihl, ni el estudiante de Praga, ni el personaje de Hoffmann, o la niña del poema de Richard Dehmel, ni el sabio del cuento de Andersen, protagonistas todos de luchas con sus sombras o reflejos, pudieron triunfar contra ellas. Todo, seres, objetos, arrastra, cadena perpetua, imposible el indulto de esta pena, su sombra inevitable.

Muy fácilmente se pasa de este tema de la sombra a otro, tema de uno de los últimos cantos de nuestro poeta: el polvo. Tiene el polvo visos de sombra, cuando su capa delgada se tiende sobre una superficie brillante. Carrera Andrade lo apostrofa de este modo:

\section{... roedor, tus dientes infinitos devoran el color, la presencia de las cosas.}

El poeta ha capitulado, sin condiciones. Porque él nos dijo paladinamente que "todo el universo es presencia". $Y$ ahora confiesa que el polvo devora la presencia de las cosas. El dilema abre su tragedia. Una de dos: o el mundo se derrumba, aquí ante nosotros, ya que era sólo presencia, y ésta es pasto inevitable del polvo; o había algo más que la presencia de las cosas, sus ausencias, sus imágenes, sus ideas. Y con éstas no puede el polvo. Carrera Andrade, que al principio de su itinerario poético desterraba terminantemente a los fantasmas de su reino se aleja ahora de nosotros, cuando cerramos su libro como una alta silueta entristecida, escoltada de sombras regresadas de su exilio. Ahora, con su metáfora, su halcón agudo siempre en la mano, va de cetrería y avizora aladas visiones, por los aires.

\section{Pedro Salinas}

1 Este estudio fué escrito especialmente para servir de prólogo a la antología poética de Carrera Andrade que la REVISTA IBEROAMERICANA publicatá en su COLECCión LITERARIA. Siendo Carrera Andrade uno de los mayores poetas de la América de hoy, nos ha parecido conveniente publicar, junto con su ensayo sobre el destino de la poesía contemporánea del Ecuador. el estudio de Salinas, para que sea así más completo el panorama de esa poesía; en la cual Carrera Andrade es la figura sobresaliente.-Nota de la Editorial. 